\title{
Bioterr Labitech, un nuevo fitonematicida a base de benzimidazol
}

\author{
Carlos A. Soria \\ Laboratorios Labitech Cia. Ltda., Quito. Pontificia Universidad Católica del Ecuador, Quito. \\ casoria@puce.edu.ec
}

\begin{abstract}
Se estudió el efecto del Bioterr Labitech, un nuevo fitonematicida a base de benzimidazol, como una alternativa al uso de nematicidas organofosforados y clorinados. Se utilizaron varios cultivos comerciales para demostrar, primero, la incidencia de diferentes géneros de nematoparásitos en dichas plantaciones, y segundo, el control de los mismos utilizando diferentes dosificaciones, únicas o repetitivas, del producto. No se reportó fitotoxicidad en banano (Musa paradisiaca), tomate de árbol (Solanum betaseum), rosas (Rosa sp.) y tomate riñón (Solanum lycopersicum), inclusive utilizando dosis por encima de las recomendadas. En los suelos de los rosales estudiados, se encontró principalmente Meloidogyne, Paratylenchus y Pratylenchus, como los más numerosos. El Bioterr redujo el número de nemátodos del suelo en rosas y tomate de árbol a niveles considerados fitopatológicamente tolerables. También hubo disminución parasitaria en las agallas radiculares causadas por Meloidogyne sp. El control dentro de las agallas parece indicar que el producto actúa, no solamente por contacto externo fuera de la raíz con parásitos libres, sino también en forma sistémica con los endoparásitos. Se reporta diferencias significativas en la sensibilidad parasitaria comparada con los saprófitos que resultan menos afectados. Se anota esta diferencia considerando la importancia de estos últimos en el mantenimiento del equilibrio bioquímico de los suelos.
\end{abstract}

PALABRAS CLAVE. nemátodos, suelo, agallas, control, Bioterr Labitech, benzimidazol, nuevo nematicida.

Bioterr Labitech, a new phytonematicide based on benzimidazole, was used as a nematicide in contrast to organophosphate and chlorinate based pesticides. Several crops were used in these experiments first, to demonstrate the incidence of different parasite genus, and second, to control them using single or repetitive doses in various concentrations. No signs of phytotoxicity were found in banana (Musa paradisiaca), tree tomatoe (Solanum betaseum), roses (Rosa sp.) and tomatoe (Solanum lycopersicum). Meloidogyne, Paratylenchus and Pratylenchus were found to be the most abundant in soils with roses and tree tomatoes. Bioterr was able to control them down to numbers considered to be phytopathologically tolerable. Meloidogyne in the root knots were also sensible to the treatment. These results seemed to indicate that Bioterr acted locally with the exoparasites and systemically with the internal endoparasites. Differences in sensitivity to Bioterr were found between parasitic 
and saprophytic nematodes. Lesser mortality was observed in saprophytes as compared to parasite's susceptibility. This difference is considered to be important do to the saprophyte contributions to the biochemical soil equilibrium of the crop.

Key words: nematodes, soil, root knots, control, Bioterr Labitech, benzimidazole, new phytonematicide.

\section{INTRODUCCION:}

Los nemátodos fitófagos, phylum Nematoda, clase Secernentea del orden Tylenchida, son las plagas que más daño causan a la agricultura (1). Se dividen en varios géneros con cerca de 2200 especies parásitas (2) que causan, entre otros problemas, pudrición o daños a la raíz de mas de 2000 especies de hortalizas, leguminosas y frutales $(3,4)$.

La infección parasitaria consume y obstruye el flujo savial, causa daños histológicos con su estilete u otro órgano similar, adaptado para penetrar células vegetales y descargar celulasas, proteinasas, lipasas, traducidas de genes que codifican el parasitismo (5).

Cuando el nematoparásito avanza hacia el conducto interno de la raíz, inyecta sus toxinas esofágicas y puede transmitir virus, bacterias $u$ hongos que ingresan a través de las heridas ocasionadas por el portador o por infiltración desde el ambiente. Se reporta, por ejemplo, infecciones con Fusarium oxysporum a través de lesiones necróticas radiculares causadas por Pratylenchus sp.

(6) o Meloidogyne sp. (2).

El ataque del género Meloidogyne es el más común (2), y se caracteriza por el aparecimiento de nódulos o agallas en la raíz, los cuales terminan obstaculizando el flujo de nutrientes y causando necrosis en al menos parte del tejido radicular infectado.

Se trata entonces de nematoparásitos diversos, algunos de vida libre o ectoparásitos (Trychodoridos) fáciles de controlar; otros facultativos, productores de huevos con matrices gelatinosas (Meloidogyne, Tylenchus, Rotylenchus) o quistes (Globodera, Heterodera) difíciles de eliminar; y además otros, endoparásitos (Pratylenchus, Rodopholus), cuyo control resulta aun más difícil, por estar protegidos dentro de tejidos radiculares, por ende, fácilmente transmisibles de una plantación a la siguiente (1). Son todos parásitos con sistemas nerviosos simples pero que les permiten movilizarse, alimentarse y reproducirse selectivamente (5).

Estos diferentes tipos de parasitismo, cada uno a su manera o en sinergia, debilitan a las plantas huéspedes ocasionando pérdidas económicas calculadas en miles de millones de dólares a nivel mundial, ya sea por mermas en la producción o por aumento considerable en la mortalidad del cultivo $(2,3,7)$.

Hasta no hace mucho, uno de los métodos para controlar fitonemátodos era el uso de bromuro de metilo. Este producto se gasifica fácilmente y penetra al interior de un suelo previamente cubierto con plásticos, logrando controlar indiscriminadamente la microfauna y la microflora. El problema radica en que además de ser un desinfectante oxidante agresivo muy 
volátil y de poca duración (2), ha probado ser un contaminante ambiental citotóxico y carcinogénico. Afortunadamente, el bromuro de metilo para uso agrícola ya no se comercializa legalmente en algunos países (3).

Otras formulaciones a base de fosforados y carbamatados, también tóxicos, tanto para el usuario como para el medio ambiente, están aún siendo utilizados en el control de nemátodos y otros problemas. En humanos y animales, el efecto de los organofosforados se mide por la inhibición de la colinesterasa, enzima que interviene en la hidrólisis de la acetocolina en las sinapsis neuronales colinérgicas de neurotransmisión. El uso continuo de estos organofosforados se asocia con daños neuronales, disminución del proceso intelectual o disfunciones cognitivas en niños y adultos expuestos directa o indirectamente a estas moléculas $(3,8,9)$.

Al momento se comercializan en el Ecuador al menos 18 formulaciones nematicidas, de las cuales 4 son organofosforados, 6 carbamatados, 4 son derivados de azodirachtinas de extractos de nim, 1 de marigold, 1 de piretrinas, 1 de hongos y 1 a base de benzimidazoles. Las formulaciones con organofosforados y carbamatados son inhibidoras de la enzima colinesterasa. Las otras formulaciones son las menos usadas y no tienen efectos conocidos.

Los benzimidazoles son conocidos como antiparasitarios gastrointestinales y pulmonares animales, también como pro- bables fungicidas agrícolas (10), pero no como fitonematicidas. El benzimidazol y la úrea sustituida son los componentes principales del Bioterr de Labitech Cia. Ltda., un producto nuevo en el área agrícola, utilizado para la desinfección y control de fitonemátodos, y libremente soluble en el agua de riego, de fácil migración por difusión y convección.

El objetivo de este estudio era el de probar la eficacia de este producto utilizando dosis efectivas en varios cultivos. Se estudiaría la toxicidad del producto en el tejido vegetal utilizando dosis exageradas, comparadas con las recomendadas, y se cuantificarían los diferentes tipos de nematoparásitos en muestras de suelo control y tratado. También se contabilizarían los nódulos formados en las raíces cuando la infección es provocada por Meloidogynea.

\section{Materiales y métodos:}

Benzimidazol, aplicaciones, plantas estudiadas:

Bioterr es un nematicida desarrollado por los Laboratorios Labitech Cia. Ltda., Quito, que consiste de $150 \mathrm{~g}$ de derivado de benzimidazol y $820 \mathrm{~g}$ de úrea amoniacal más excipiente, por $\mathrm{Kg}$.

El producto fue aplicado, para cada cultivo estudiado, en drench o por fertirriego, de acuerdo con las instrucciones del fabricante. Previo a la aplicación, el suelo debe estar húmedo a capacidad de campo, 
para favorecer la penetración del producto a por lo menos $15 \mathrm{~cm}$ de profundidad, hacia el sector de las raíces secundarias donde se localiza mayormente la infección (11). El resultado de los experimentos dependerá totalmente de esta condición de arrastre molecular, caso contrario, su actividad permanecerá en las capas superficiales del suelo y no alcanzará el objetivo deseado.

Las plantas utilizadas en estos experimentos provenían de plantaciones diseñadas para producción comercial. Los cultivos de banano (Musa paradisiaca) pertenecían a la zona de Santo Domingo de los Colorados; las rosas (Rosa sp.) de El Quinche, en Pichincha; el tomate riñón (Solanum lycopersicum) en Ibarra, Imbabura y en Baños Tungurahua y el tomate de árbol (Solanum betaseum) en la zona de Puela, Chimborazo.

\section{Toxicidad de Bioterr:}

Se estudió toxicidad aplicando 2 y 4 veces la dosis recomendada para plantas adultas de: banano, tomate de árbol, rosas y tomate riñón. Como control se separaron 25 plantas de cada cultivo, las cuales no recibieron tratamiento, 25 para la aplicación con 2 dosis y otras 25 , igual de cada cultivo, tratadas con 4 dosis. El experimento se volvió a repetir en circunstancias similares en 2 ocasiones mas.

Durante 7 días posteriores a la aplicación del Bioterr, se observó el estado de cada una de las plantas tratadas, comparándolas con los controles. Se reportó la presencia o ausencia de marchitez o cambios en la coloración de las hojas.

\section{Conteo e identificación de nemátodos:}

Para estos experimentos se utilizaron tres hectáreas de cultivos comerciales de variedades de rosas con aproximadamente 70000 plantas adultas por hectárea. Una de estas hectáreas no recibió tratamiento y sirvió de control. A las otras dos se les administró por fertirriego, uno o dos tratamientos a 15 días de intervalo, cada uno equivalente a $200 \mathrm{mg}$ en $100 \mathrm{cc}$ de agua de riego por planta y por tratamiento.

Cinco días posteriores a cada aplicación y utilizando un sacabocados de acero inoxidable de $5 \mathrm{~cm}$ de diámetro y $50 \mathrm{~cm}$ de largo, se tomaron 10 ó 20 muestras de suelo al azar, en zigzag, a unos $15 \mathrm{~cm}$ de profundidad, donde deberían encontrarse más raíces secundarias y la mayor distribución horizontal y vertical de nemátodos (11).

Las muestras, cada una de aproximadamente $100 \mathrm{~g}$, se mezclaron en una funda, obteniendo aproximadamente $1 \mathrm{~kg}$ de suelo de la plantación control y otros $2 \mathrm{~kg}$, en funda separada, con las muestras de suelos que recibieron tratamiento. Este proceso se repitió cuando se aplicó el segundo tratamiento, tanto con los controles como con las plantas tratadas.

De cada total de muestra bien mezclada, se pesó $20 \mathrm{~g}$ de suelo que fue suspendido con agitación continua durante 2 min en $250 \mathrm{cc}$ de agua de la llave reposada (durante la noche) en botellas cilíndricas de boca ancha, de $500 \mathrm{cc}$ de capacidad. La agitación se realizó inicialmente con movimientos rápidos rotatorios que fueron disminuyendo progresivamente de intensidad, luego se dejó decantar durante un minuto y el sobrenadante fue filtrado por malla de 
tela fina para separar arcillas o limo que pudieran enturbiar los lavados. A continuación se pasó por una malla de $40 \mathrm{um}$, y lo que quedó en la malla fue lavado con $20 \mathrm{cc}$ de agua y colectado en un vaso de precipitación. De esta fracción, se tomó una muestra volumétrica de $5 \mathrm{cc}$, la cual fue depositada en una caja petri pequeña para su conteo o identificación en 25 campos, usando un estéreo microscopio con 50 aumentos.

Se reportó el total observado por género, incluyendo estadíos larvales y adultos por volumen de muestra. El resultado obtenido en cada muestra se multiplicó por 20 y se reportó como número total por género (o grupo de saprófitos) por $100 \mathrm{~g}$ de suelo. Los conteos corresponden al promedio de tres repeticiones.

Otros experimentos se realizaron con Tomate de árbol adulto. En tres estudios similares efectuados a un mes de intervalo, grupos de 100 plantas recibieron diferentes tratamientos con una única dosis sea de $250,500,1000$ o $5000 \mathrm{mg}$ en $200 \mathrm{cc}$ de agua por planta, aplicados en drench, alrededor de la corona, con el suelo a capacidad de campo. Los grupos control no recibieron tratamiento durante el tiempo del experimento. Cinco días posteriores al tratamiento se procedió a tomar cinco muestras de suelo por cada grupo tratado, incluyendo los controles, con una metodología similar a la de las rosas.

\section{Nódulos en las raíces:}

Se estudiaron los nódulos de las raíces de plantas de tomate de árbol infectados con nemátodos. Para el efecto se descubrieron, a una profundidad de $15 \mathrm{~cm}$, algunas raíces de 50 plantas que sirvieron de con- trol, y se colectó en una funda entre 5 a 10 $\mathrm{g}$ de raíces por planta, después se volvieron a tapar las raíces expuestas. La misma operación se realizó con idéntico número de plantas que recibieron tratamiento con 500 mg por planta, y con otro grupo similar, tratado con $1000 \mathrm{mg}$.

Las raíces así colectadas para cada grupo fueron mezcladas manualmente en cada funda, luego se pesaron $100 \mathrm{~g}$ de raíces en las que se contaron y reportaron nódulos de $3 \mathrm{~mm}$ o más de diámetro. Las plantas controles y experimentales, al momento del tratamiento, tenían tres meses de sembradas. Los muestreos y conteos de los controles y de las plantas tratadas se hicieron a los 30, 60 y 90 días posteriores a la aplicación del Bioterr. El número de nódulos reportados, corresponden al promedio de tres repeticiones.

Las raíces de diez plantas controles y diez experimentales de seis meses de edad, que recibieron $1000 \mathrm{mg}$ a los 90 días de plantadas fueron expuestas, seleccionándose dos nódulos (de $3 \mathrm{~mm}$ o más) representativos por planta, en total 40,20 de las plantas controles y 20 experimentales.

Los nódulos fueron bien lavados con agua de la llave y secados con papel absorbente, luego divididos en grupos de cinco nódulos, cuatro grupos repetitivos para los controles y cuatro para los experimentales. Los cinco nódulos de cada grupo fueron abiertos y desmenuzados cuidadosamente con agujas de disección en $5 \mathrm{cc}$ de agua. Se agitó suavemente el tejido en el agua por aproximadamente $3 \mathrm{~min}$ y se observó detenidamente en 25 campos microscópicos por muestra analizada, reportando la presencia o ausencia de parásitos o huevos. 
Se realizaron análisis de varianza para detectar diferencias estadísticas en las muestras ensayadas y adicionalmente pruebas de significación de Tukey al 0.05 .

\section{Resultados}

Dosificaciones óptimas de Bioterr Labitech, fueron aplicadas a banano, tomate de árbol, rosas y tomate riñón, según instrucciones del fabricante. La fórmula es muy soluble en diferentes aguas de riego y es aplicada inmediatamente después de la dilución en diferentes volúmenes, vía drench o fertirriego, basados en experimentos previos en varios cultivos jóvenes y adultos que han sido tratados durante los últimos 6 años que se ha venido estudiando este producto (datos no reportados).

Dosis altas, por encima de lo recomendado, también se aplicaron en unas 25 plantas de cada especie, en banano, tomate de árbol, rosas y tomate riñón para estudiar fitotoxicidad (Tabla 1). Durante el experimento, incluyendo dos repeticiones, no se notaron síntomas de marchitez o cambios en la coloración de las hojas durante las observaciones diarias que se realizaron hasta los siete días posteriores a la aplicación de estos benzimidazoles.

Se estudió el efecto de uno o dos tratamientos cada uno de $200 \mathrm{mg}$ por planta, aplicados por fertirriego a unas 140000 plantas de rosas adultas de diferentes variedades comerciales con 15 días de intervalo entre el primer tratamiento y el segundo (Tabla 2). Los controles, consistentes en unas 70000 plantas, no recibieron tratamiento durante el tiempo que duró el experimento. Los resultados se expresaron como número promedio de nemátodos por género en $100 \mathrm{~g}$ de suelo, tanto para los controles como para las muestras tratadas. Los muestreos y conteos se realizaron a los 5 días posteriores a la primera o segunda aplicación.

Tabla 1. Toxicidad de Bioterr - benzimidazol, aplicado 2 y 4 veces la dosis recomendada para diferentes cultivos.

\begin{tabular}{|c|c|c|c|c|c|c|}
\hline \multirow{2}{*}{$\begin{array}{c}\text { Cultivo: } \\
\text { observaciones } \\
\text { en } 25 \text { plantas } \\
\text { adultas }\end{array}$} & \multicolumn{2}{|c|}{ Observaciones: marchitez o cambios en la coloración de las hojas } \\
\cline { 2 - 7 } & $\mathrm{A}$ & $\mathrm{B}$ & $\mathrm{A}$ & $\mathrm{B}$ & $\mathrm{A}$ & $\mathrm{C}$ Control \\
\hline \hline Banano & 0 & 0 & 10 & 0 & 20 & 0 \\
\hline Tomate de árbol & 0 & 0 & 1 & 0 & 2 & 0 \\
\hline Rosas & 0 & 0 & 0.4 & 0 & 0.8 & 0 \\
\hline Tomate riñón & 0 & 0 & 0.1 & 0 & 0.2 & 0 \\
\hline
\end{tabular}

$* \mathrm{~A}=\mathrm{g}$ de Bioterr aplicado por planta, $\mathrm{B}=$ observaciones realizadas durante 7 días consecutivos posteriores a la aplicación del Bioterr. El 0 indica que no se observó ni marchitez ni cambio de coloración en las hojas. Los resultados corresponden a lo observado diariamente en 3 experimentos similares. 
Tabla 2. Control de nemátodos en rosas con uno y dos tratamientos de Bioterr (200 mg/100 cc/planta/tratamiento) a 15 días intervalos.

\begin{tabular}{|l|c|c|c|c|}
\hline \multirow{2}{*}{$\begin{array}{c}\text { Género } \\
\text { o grupo }\end{array}$} & \multicolumn{4}{|c|}{ \# nemátodos promedio/100 g de suelo muestreado } \\
\cline { 2 - 5 } & 1 & 2 & 1 & 2 \\
\cline { 2 - 5 } & 600 & 720 & 80 & 0 \\
\hline Meloidogyne & 240 & 180 & 0 & 0 \\
\hline Pratylenchus & 300 & 200 & 40 & 0 \\
\hline Paratylenchus & 80 & 120 & 0 & 0 \\
\hline Trichodorus & 40 & 60 & 0 & 0 \\
\hline Tylénchidos & 440 & 520 & 320 & 200 \\
\hline Saprófitos & & &
\end{tabular}

*Muestreos y conteos, a los 5 días posteriores a cada aplicación. Los resultados corresponden al promedio de 3 repeticiones.

En estos estudios se reportó: Meloidogyne sp. de la familia Heteroderidae como parásitos delgados, cauda redonda y pocas hembras oviplenas piriformes. Paratylenchus sp., familia Paratylenchidae, que aparecen en forma de media luna y cauda aguzada. Pratylenchus sp., de la familia Hoplolaimidae, caracterizados por tener una región cefálica y caudal redondeada. Trichodorus sp., familia Trichodoridae, de apariencia cilíndrica . De la misma forma se reportó tylenchidos de la familia Tylenchidae que agrupa a varios nemátodos delgados y caudalmente filiformes.

De los conteos realizados en los grupos controles (Tabla 2), se pudo observar una infección considerable de nemátodos parásitos (entre 180 hasta 720 individuos por $100 \mathrm{~g}$ de suelo), en los géneros Meloidogyne, Pratylenchus y Paratylenchus, así como una población considerable de saprófitos entre 440 y 520 individuos. En los mismos controles se detectó Trichodorus y tylenchidos presentes en pequeñas poblaciones (entre 40 y 120 individuos). En el caso particular de los Tylenchidos, cuyas poblaciones fueron pequeñas, no hubo diferencias significativas entre grupos controles y tratados, probablemente porque se encontraron pocos individuos $(\mathrm{p}=0.08)$.

Una vez administrado el primer tratamiento, se notó una disminución significativa $(\mathrm{p}<0.05)$ en el número de nemátodos de todos los géneros parásitos (entre 0 y 80 individuos), más aun después del segundo tratamiento. Los saprófitos también disminuyeron con el primer tratamiento (320) y más con el segundo (200), sin embargo, con el primer tratamiento, no se encontró una diferencia significativa con el control $(\mathrm{p}=0.085)$.

Diferentes concentraciones de benzimidazoles se aplicaron por una sola vez en plantas adultas de tomate de árbol (Tabla 3). Se realizaron tres repeticiones de este experimento y se expresaron los resultados 
Tabla 3. Tomate de árbol: control de nemátodos con Bioterr usando diferentes concentraciones por tratamiento.

\begin{tabular}{|c|c|cccc|}
\hline \begin{tabular}{c} 
Tomate: \\
\multirow{1}{100}{$\begin{array}{c}\text { plantas/ } \\
\text { dosis / prueba }\end{array}$}
\end{tabular} & Control & \multicolumn{4}{|c|}{ \# de nemátodos / 100 g de suelo } \\
\cline { 3 - 6 } & & \multicolumn{4}{c|}{ dosis en $\mathrm{mg} / 200 \mathrm{cc} /$ planta } \\
\cline { 3 - 6 } \# de prueba & 250 & 500 & 1000 & 5000 \\
\hline 1 & 1700 & 400 & 160 & 200 & 2 \\
\hline 1 & 840 & 280 & 120 & 40 & 0 \\
\hline 3 & 1620 & 320 & 60 & 0 & 0 \\
\hline
\end{tabular}

como conteos totales de nemátodos parásitos por $100 \mathrm{~g}$ de suelo (no se contabilizaron saprófitos). Las dosis aplicadas fueron de 250, 500, 1000 o $5000 \mathrm{mg}$ de Bioterr por planta.

Los controles indicaron una infección de hasta 1840 nematoparásitos por $100 \mathrm{~g}$ de suelo, números que fueron disminuyendo significativamente (entre 280 a 400 individuos) cuando se aplicaron $250 \mathrm{mg}$ por planta. Una reducción aun más significativa en el número de nemátodos (entre 160 a
0) fue reportado con dosis de $500 \mathrm{mg}$ o más, por planta $(\mathrm{p}=0.000)$.

Infecciones, especialmente de Meloidogyne, se reportaron estudiando los nódulos que aparecen en las raíces infectadas. Nódulos de $3 \mathrm{~mm}$ de diámetro o más, se contaron en $100 \mathrm{~g}$ de raíces de tomate de árbol de 4, 5 y 6 meses de edad al momento del muestreo (Tabla 4). Se observó en los controles que el número de nódulos aumentaba de 96 en las plantas control de cuatro meses de edad hasta 192

Tabla 4. Nódulos por $100 \mathrm{~g}$ de raíces de tomate de árbol colectadas de 50 plantas por cada grupo de estudio: control (sin tratamiento), o con 500 o $1000 \mathrm{mg}$ de Bioterr por planta, aplicado 90 días después de la plantación.

\begin{tabular}{|c|c|c|c|}
\hline \multirow{2}{*}{$\begin{array}{l}\text { Tomate: } 50 \text { plantas/ } \\
\text { control / dosis. }\end{array}$} & \multicolumn{3}{|c|}{ \# de nódulos $\mathbf{( = 3 ~ m m ) ~ / ~ 1 0 0 ~ g ~ d e ~ r a i ́ c e s ~}$} \\
\cline { 2 - 4 } & Control & \multicolumn{2}{|c|}{ Dosis / planta } \\
\hline $\begin{array}{l}\text { Edad de las plantas } \\
\text { al momento del muestreo }\end{array}$ & & \multicolumn{2}{|c|}{$500 \mathrm{mg}$} \\
\hline 4 meses & 90 & 9 & 41 \\
\hline 5 meses & 125 & 38 & 33 \\
\hline 6 meses & 192 & 25 & 29 \\
\hline
\end{tabular}

* Muestreos y conteos a los 30, 60, 90 días posteriores al tratamiento. Los resultados corresponden al promedio de 3 repeticiones. 
nódulos de $3 \mathrm{~mm}$ o más cuando fueron estudiadas a los 6 meses de edad. En cambio, tanto en las plantas que recibieron 500 como $1000 \mathrm{mg}$ por individuo, el número de nódulos se mantuvo bajo, entre 41 y 9 , cuyas diferencias frente al control, en función de la edad de las plantas, son significativas $(\mathrm{p}=0.000)$.

No se observaron microscópicamente nemátodos en 20 nódulos colectados, dos de cada una de 10 plantas de 6 meses de edad que fueron tratadas hace 3 meses, individualmente, con $1000 \mathrm{mg}$ de Bioterr (Tabla 5), mientras que aquellos nódulos provenientes de las 10 plantas sin tratamiento y que sirvieron de control, sí estaban todos infectados con hembras (algunas oviplenas), huevos o larvas pequeñas.

\section{Discusión:}

Se han venido utilizando nematicidas, como los organofosforados por mucho tiempo, a pesar de sus efectos tóxicos, como inhibidores que son de las colinesterasas, enzimas esterasas, encargadas de hidrolizar los ésteres de colina, como la acetocolina, que se acumulan en las sináp- sis neuronales y que deben ser continuamente regenerados durante el funcionamiento nervioso.

En los últimos años han aparecido otras alternativas en el control de los nemátodos, con el uso de derivados del nim, marigold o piretro y de algunos hongos, cuyos efectos no han sido reportados (12).

Los benzimidazoles son compuestos orgánicos cíclicos nitrogenados con intensa actividad antiparasitaria en animales y en el hombre. Bioterr de Labitech Cia. Ltda., a base de benzimidazoles para uso agrícola, nos permitió estudiar su efecto novedoso en el control de los nemátodos del suelo (12).

Partimos por entender las dosis recomendadas por el fabricante, las cuales varían de acuerdo con el tipo de cultivo, o si este es joven o adulto. Se conoce, por ejemplo, que las infecciones con nemátodos y su incidencia dependerá de la edad de las plantas infectadas (11). Plantas grandes, con mayor cantidad de raíz (banano), reciben concentraciones más altas $(2500$ hasta $5000 \mathrm{mg}$ por planta), mientras que otras más pequeñas (tomate riñón), pueden ser tratadas con cantidades menores (50 mg por planta).

Estas recomendaciones, aplicadas en

Tabla 5. Presencia (si) o ausencia (no) de nemátodos en cinco nódulos (cuatro grupos o repeticiones) de raíces de 20 plantas de tomate de árbol de 6 meses de edad (dos nódulos por planta), tratados o no (diez experimentales, diez controles) a los 90 días de plantados, con una dosis de $1000 \mathrm{mg}$ de Bioterr por planta.

\begin{tabular}{|c|c|c|}
\hline Grupo & Control & Experimental \\
\hline 1 & $\mathrm{Si}$ & No \\
\hline 2 & $\mathrm{Si}$ & No \\
\hline 3 & $\mathrm{Si}$ & No \\
\hline 4 & $\mathrm{Si}$ & No \\
\hline
\end{tabular}


cierto volumen de agua, que depende del área por cubrir, están relacionadas con la máxima cobertura de probables áreas de infección (11) en o cerca de las raíces superficiales, profundas, abundantes $\mathrm{o}$ escasas, que naturalmente difieren de acuerdo con el tipo de cultivo.

Todo esto ligado a un costo - beneficio y a las relaciones del principio activo con el parásito y de éste con el suelo, su humedad, la cobertura vegetal, abonadura y la temperatura del ambiente, todos importantes en el desarrollo del ciclo de vida del parásito. La presencia de fertilizantes como el fósforo inorgánico por ejemplo, reducen significativamente la presencia de hembras y con ellas, la población de nemátodos (13).

La capacidad del Bioterr de disolverse totalmente, facilita su uso. A esto se suma el hecho de ser aparentemente un producto no tóxico, de sello verde, cuyas moléculas activas, además de actuar por contacto, probablemente pueden ser absorbidas o acarreadas a través de la raíz hacia los tejidos infectados cercanos. La ausencia de nemátodos dentro de los nódulos de las raíces tratadas (Tabla 5), se considera como indicativo de absorción del benzimidazol al tejido radicular, lo que produjo el control parasitario dentro de las agallas. Los otros componentes, por ejemplo la úrea sustituida amoniacal, actuarán como moléculas catiónicas con poder surfactante y tensoactivo que probablemente ayudarían en la penetración o acarreo del benzimidazol. Se sabe que la absorción radicular de un pesticida en solución acuosa, dependerá de su formulación y de la presencia de ácidos orgánicos como los húmicos y fúlvicos (14).

Las observaciones que se hicieron sobre la toxicidad del Bioterr después de aplicar 2 y 4 veces la dosis recomendada en varios cultivos, observados diariamente durante una semana (Tabla 1), no dieron indicios de marchitez o de cambios en la coloración de las hojas. Generalmente, cuando hay fitotoxicidad se observan en pocas horas o días cambios visibles en el color de la hoja con decaimiento o marchitez. Según lo reportado, parece haber un rango significativo de tolerancia, incluso con dosis altas .

Ameritaría hacer más estudios sobre el uso seguro del benzimidazol en varios cultivos, como por ejemplo: tiempos de exposición más largos, uso frecuente de la molécula durante uno o más ciclos de la planta, observaciones microscópicas de los tejidos de raíz, tallo y hojas, vida media de la molécula en los diferentes tipos de suelo semi superficiales y profundos y en los tejidos vegetales, combinado con estudios de calidad y rendimiento en los diferentes cultivos. Todo esto, en concordancia con las oportunidades y desafíos que conlleva el tratar de descubrir nuevas drogas, modificarlas o reportarlas como nuevos usos en mercados que a lo mejor resultan insuficientes para justificar, a veces, estos estudios (8).

De lo encontrado en rosas (Tabla 2), se desprende que estos cultivos son bastante susceptibles al ataque de varios géneros de nemátodos polifitófagos, de los cuales los géneros Meloidogyne, Paratylenchus y Pratylenchus, fueron los más abundantes en el estudio de los grupos control. Otros como Trychodorus y tylénchidos se encontraron en números promedio significativamente más bajos, pero no por eso pueden ser considerados infectivamente menos importantes. La presencia de 
Trychodorus por ejemplo, aunque en números bajos (promedio entre 80 y 120 por $100 \mathrm{~g}$ de suelo), sigue siendo de gran importancia, por estar catalogado como transmisor viral (15).

El control de la infección, evidenciado por la reducción significativa en el número de todos los géneros de nemátodos estudiados fue claro, incluso cuando se aplicó el primer tratamiento y más aun después de la segunda dosis.

El benzimidazol, una vez en contacto con el nemátodo, sea afuera, en el suelo o dentro en la raíz, probablemente es absorbido al sistema muscular del parásito, provocando contracciones y relajaciones seguidas de parálisis debido a la inhibición enzimática del ácido fumárico o succínico con incapacidad para metabolizar la glucosa muscular. Interacciones del benzimidazol o inclusive del excipiente úrea amoniacal, con las glicoproteínas o con los esteroles de las membranas del parásito (16), podría anular sus resistencias y causar parálisis neuromuscular (17). Estos posibles efectos biomoleculares podrían convertirse en herramientas para estudiar expresiones genéticas neuronales en sistemas conservativos parasitarios relativamente menos complicados (3).

Resulta interesante la presencia de saprófitos, caracterizados por ser más grandes y fuertes, que si bien hay mortalidad en presencia del Bioterr, especialmente después de un segundo tratamiento, ésta no es tan alta como la que se observa con los nemátodos parásitos. Esta selectividad o poca mortalidad de los saprófitos, probablemente se puede explicar porque éstos se alimentan de tejidos muertos, en vez de tejidos vivos de los cuales podrían absorber principios activos sistémicos (1) con antiparasitarios.

La presencia de saprófitos se convierte en una ventaja para las plantas, porque al ser convertidores de tejidos muertos en substratos asimilables, se vuelven remodeladores y acondicionadores iónicos de los suelos. Su actividad permite la liberación de nutrientes que pueden estar localizados en ciertos nichos y no en otros (18), causan un mejor aprovechamiento del agua y del oxígeno del suelo (9) y estimulan el crecimiento de microorganismos antagónicos como es el caso de Bacillus thuringiensis, cuyas exoproteinas cristalizables también podrían controlar fitonemátodos (19).

Los estudios realizados en tomate de árbol con diferentes dosis (Tabla 3), dieron como resultado el control significativo de los nemátodos. Incluso utilizando dosis bajas, ya se observó una reducción en la población, número que fue disminuyendo significativamente al aumentar la dosificación. No se encontraron diferencias al usar dosis de $1000 \mathrm{mg}(\mathrm{M}=20$ nemátodos por $100 \mathrm{~g}$ de suelo) o $5000 \mathrm{mg}$ (0 nemátodos por $100 \mathrm{~g}$ de suelo) por planta, indicando de nuevo que los $500 \mathrm{mg}$ por planta adulta de tomate de árbol es el tratamiento recomendado, tanto por efectividad como por costo para reducir significativamente la población de nemátodos ( $\mathrm{p}$ $<0.005$ ).

Hay que insistir en que los conteos reportados son relativos, como se puede apreciar cuando en las muestras analizadas, tratadas con dosis altas, muy bien podría aparecer un único nemátodo en los 5 cc de muestra y en los 25 campos analizados, lo que según la metodología de 
este análisis, significaría la presencia de 20 nemátodos en $100 \mathrm{~g}$ de suelo. Ventajosamente, los conteos bajos obtenidos en las muestras tratadas, comparadas con los números altos de los controles, son significativamente diferentes. Podríamos, por lo tanto, asumir que la reducción de nemátodos, después del tratamiento, descendió a niveles considerados fitopatológicamente tolerables.

Datos parecidos, que igual sitúan al Bioterr como nematicida sistémico, se pudo observar al estudiar los nódulos radiculares infectivos de $3 \mathrm{~mm}$ de diámetro o más, en tomate de árbol. El ataque del género Meloidogyne, de gran importancia agronómica, es peculiar en más de 3000 variedades de cultivos (20) y se caracteriza por la respuesta del tejido radicular que estimula la multiplicación de células gigantes, las cuales tienden a obstaculizar el avance del parásito, formando nódulos o agallas que crecen en número y en diámetro, a medida que aumenta el tiempo de infección.

Meloidogyne sp., especialmente sus hembras y primeros estados larvarios, viven y ovopositan en el nódulo, pero su presencia causa hipersensibilidad en las células vegetales debido a la presencia de toxinas, celulasas, proteinasas, radicales oxigenados de alta reactividad, productos de los genes del parasitismo que terminan suprimiendo procesos fotosintéticos y de respiración. La planta queda disminuida en el flujo de nutrientes y agua, por necrosis radicular y por el aparecimiento de infecciones bacterianas, fungosas y virales ante la pérdida de mecanismos de resistencia vegetal (2).

Al estudiar las raíces controles se observa un aumento constante en el número de nódulos proporcional a la edad de las plantas y al tiempo de infección (Tabla 4). Pero en los grupos tratados, el número de nódulos de $3 \mathrm{~mm}$ o más, es bajo y con el tiempo, a diferencia del grupo control, el número de nódulos parece mantenerse, aun utilizando dosis altas del nematicida. Se observó también una renovación de raicillas en los grupos tratados, a diferencia del grupo control (datos no reportados).

Esto se explica porque una vez iniciado el daño del tejido con el aparecimiento de un complejo de células gigantes multinucleadas alimentadoras del parásito y el consecutivo aparecimiento de los nódulos por la proliferación de las células de los alrededores (7), éstos permanecen aun en ausencia de los nemátodos que aparentemente han sido controlados por el Bioterr (Tabla 5), probablemente debido a su sistemicidad.

Las observaciones microscópicas de estos nódulos tratados indican ausencia de parásitos anidados $\mathrm{y}$, al tacto, el tejido nodal aparece blando en las plantas que recibieron tratamiento. Mas aun, en función de tiempos largos de observación, se espera que el tejido necrosado, pero sin parásitos, no haya aumentado de espesor y desaparezca junto con los restos de las raíces obstruidas y en su lugar aparezcan nuevos brotes radiculares secundarios sanos (datos no reportados).

La aparente sistemicidad del producto es importante, especialmente en el control de endoparásitos (Pratylenchus) o parásitos facultativos (Meloidogyne) (1), considerando que estos nemátodos se alimentan de biomoléculas a través de tubos alimentadores conectados a las membra- 
nas y al retículo endoplásmico de las células gigantes (7).

El número de nódulos promedio, que se mantiene bajo (Tabla 5) y la ausencia de parásitos en los mismos (Tabla 6) en plantas que recibieron tratamiento hace 90 días, podría explicarse porque los benzimidazoles no sufren fácilmente biotransformaciones (10) por descarboxilización, lo que permitiría que estas moléculas puedan permanecer activas en el suelo por algún tiempo. Esta es una propiedad interesante, que significaría un ahorro en el tratamiento contra estos nemátodos, cuyo ciclo de vida, consistente de 4 mudas, desde huevo a adulto (2), y que en nuestros suelos de altura, se prolonga entre 25 hasta 30 días, dependiendo si las temperaturas del ambiente permanecen temporalmente cálidas o frías.

\section{LITERATURA CITADA:}

1. Lamberti F., Greco N., Basile M., 1986. Treatments of soil-nematological aspects. Bulletin OEPP/EPPO Bulletin 16, $327-$ 333.

2. Leonard D., 1991. The nematode. Horticulture 69 (3), 1-7.

3. Fleming C., McKinney S., McMaster S., Johnston M., Donnelly P., Kimber M., Maule A., 2007. Getting to the root of neuronal signaling in plant-parasitic nematodes using RNA interference. Nematology 9 (3), 301-315.

4. Ubidia P., Soria C., 2006. Revisión de efectos y daños causados por los nemátodos fitoparásitos en cultivos importantes en la producción agrícola. XXX Jornadas Nacionales de Biología. Sociedad Ecuatoriana de Biología y Pontificia Universidad Católica del Ecuador. Libro de resúmenes, p. 112.
5. Zinovéva S., Vasyukova, N., Ozeretskovskaya O., 2004. Biochemical aspects of plant interactions with phytoparasitic nematodes: a review. Applied Biochemistry and Microbiology 40 (2), 111-119.

6. Castillo P., Jimenez R., Gomez A., Vovlas N., 1995. Parasitism of the root-lesion nematode Pratylenchus thornei on chickpea. Plant Pathology 44, 728-733.

7. Hofmann J., Grundler M., 2007. How do nematodes get their sweets? Solute supply to sedentary plant-parasitic nematodes. Nematology 9 (4), 451-458.

8. Pink R., Hudson A., Mourie's M., Bendig M., 2005. Opportunities and challenges in antiparasitic drug discovery. Nature reviews 4, 727-740.

9. Blouin M., Zuily-Fodil Y., Pham-Thi A., Laffray D., Reversat G., Pando A., Tondoh J., Lavelle P., 2005. Belowground organism activities affect plant aboveground phenotype, inducing plant tolerance to parasites. Ecology letters 8, 202-208.

10. Ballinger D., Kollmorgen J., 1986. Control of take-all of wheat in the field with benzimidazole and triazole fungicides applied at seeding. Plant Pathology 35, 67-73.

11. Araya M., Vargas A., Cheves A., 1999. Nematode distribution in roots of banana (Musa AAA cv. Valery) in relation to plant height, distance from the pseudostem and soil depth. Nematology 1 (78), 711-716.

12. Soria C., 2006. Benzimidazoles en el control de nemátodos. XXX Jornadas Nacionales de Biología. Sociedad Ecuatoriana de Biología y Pontificia Universidad Católica del Ecuador. Libro de resúmenes, p. 51-52.

13. Waceke J., Waudo S., Sikora R., 2002. Effect of inorganic phosphatic fertilizers on the efficacy of an arbuscular mycorrhiza fungus against a root-knot nematode on pyrethrum. International Journal of Pest Management 48 (4), 307-313. 
14. Kyriakopoulos G., Doulia D., 2006. Adsorption of pesticides on carbonaceous and polymeric materials from aqueous solutions: a review. Separation and Purification Reviews 35, 97-191.

15. González L. 1985. Introducción a la Fitopatología. 4ta Edición, Editoril IICA, San José de Costa Rica, Costa Rica, p. 57-64.

16. Vervelde L., Van Leeuwen M., Kruidenier M., Kooyman F., Huntley J., Va Die I., Cornelissen A., 2002. Protection studies with recombinant excretory / secretory proteins of Haemonchus contortus. Parasite Immunology 24, 189-201.

17. Kerboeuf D., Riou M., 2006. Nematodes as Models for the Study of the Regulation of Activity of P-glycoproteins in Multidrug Resistance (MDR). Anti-Infective Agents in Medicinal Chemistry 5, 389-402.
18. Wurst S., Langel R., Scheu S., 2005. Do endogeic earthworms change Plant competition? A microcosm study. Plant and Soil 271, 123-130.

19. Li Xiang-Qian, Tan A., Aroian R., 2007. Resistance to root-knot nematode in tomato roots expressing a nematicidal Bacillus thuringiensis cristal protein. Plant Biotechnology Journal 5, 455-464.

20. Castagnone P., 2002. Genetic variability in parthenogenetic root-Knot nematodes, Meloidogyne spp., and their ability to overcome plant resistance genes. Nematology 4, 605-608. 